\title{
PERILAKU KELOMPOK PETANI KOPI RAKYAT MENGIKUTI KELOMPOK DAN YANG TIDAK MENGIKUTI KELOMPOK TANI DI KECAMATAN PANTI KABUPATEN JEMBER
}

\author{
Irwan Gunawan 1)*, Cakti Indra Gunawan ${ }^{2)}$, Budi Prihatminingtyas ${ }^{3)}$ \\ 1)*, 2), 3) Universitas Tribuwana Tunggadewi \\ e-mail : Irwangunawan093@gmail.com ${ }^{1)^{*}}$, \\ Cakti.gunawan@gmail.com ${ }^{2)}$,prahatminityas@gmail.com ${ }^{3)}$
}

\begin{abstract}
ABSTRAK
Indonesia termasuk lima besar eksportir kopi dunia, negara tujuan utama adalah negaranegara eropa seperti Jerman, Belanda, Italia, selain itu yang cukup kontinu adalah ekspor ke Amerika Serikat. Lebih lanjut, suatu laporan oleh Organisasi Kopi Internasional menurut ICO, 2005,menunjukkan bahwa harga kopi mengalami penurunan dari tahun ke tahun. Pada tahun 2005, harga kopi ekspor Indonesia menurun dua persen. Walaupun kopi merupakan komoditi ekspor penting, ketidakpastian harga dan selalu terjadi penurunan harga dipasar ekspor maka perlu menyoroti pentingnya pasar kopi domestik. Rata-rata biaya produksi pada petani yang mengikuti kelompok sebesar Rp 7.626 .722 per hektar, dengan tingkat penerimaan sebesar Rp 23.430.794per hektar, dan nilai R/C yang di peroleh sebesar 3,18, berarti setiap rupiah biaya yang dikeluarkan dapat menghasilkan penerimaan sebesar Rp 3,18. Dengan demikian maka usahatani kopi rakyat yang mengikuti kelompok sudah efisien. Petani yang tidak mengikuti kelompok rata-rata biaya produksi sebesar Rp 5.786,003 per hektar, dengan tingkat penerimaan sebesar Rp 11.820.368per hektar,dan nilai $\mathrm{R} / \mathrm{C}$ yang di peroleh sebesar 2,08. Artinya setiap rupiah biaya yang dikeluarkan dapat menghasilkan penerimaan sebesar Rp 2,08. Test Of Homogenity of Variances" di atas diketahui nilai signifikansi. Variabel kopi rakyat berkelompok dan kopi rakyat tidak berkelompok adalah sebesar 0,343. Karena nilai Sig 0,343>0,05 maka sebagaimana dasar pengambilan keputusan dalam uji homogenitas diatas, dapat disimpulkan bahwa varians data kopi rakyat berkelompok dan kopi rakyat tidak berkelompok adalah sama atau homogen.Berdasarkan uji ANOVA yang dilakukan terhadap produksi diperoleh hasil $F_{\text {hitung }}$ $=0,487 \mathrm{df} 3=1, \mathrm{df} 4=78$. Pengambilan keputusan berdasarkan perbandingan $\mathrm{F}_{\text {hitung }}$ danFtabel yaitu jika $F_{\text {hitung }}>\mathrm{F}_{\text {tabel }}$ maka $\mathrm{H}_{0}$ ditolak, $\mathrm{F}_{\text {hitung }}<\mathrm{F}_{\text {tabel }}$ maka $\mathrm{H}_{0}$ diterima. $\mathrm{F}_{\text {hitung }}$ dari output adalah 0,487 sedangkan $\mathrm{F}_{\text {tabel }}$ bisa dihitung pada tabel $\mathrm{F}$. Dari tabel $\mathrm{F}$ didapat angka 3.96347, F tabel bisa diperoleh secara praktis menggunakan software Excel dengan menulis pada sel = FINV $\left(\mathbf{0 , 0 5 ; 1 ; 7 8 )}\right.$. Dengan tabel seperti diatas terlihat bahwa $F_{\text {hitung }}<F_{\text {tabel, }}, 0,487$ $<3.96347$ maka $\mathrm{H}_{0}$ diterima yang artinya tidak terdapat perbedaan yang signifikan, maka tidak perlu dilanjutkan dengan uji lanjutan

Kata Kunci :Kopi, Kelompok Petani, Tidak Ikut Kelompok Petani
\end{abstract}




\section{PENDAHULUAN}

Kopi merupakan salah satu komoditas perdagangan strategis dan memegang peranan penting bagi perekonomian nasional hingga akhir tahun 1990-an. Manfaat dari kopi ini antara lain sebagai : penyedia lapangan kerja, sumber pendapatan dan devisa negara bagi Indonesia, sehingga prospek ke depan masih sangat menjanjikan. Sebagian besar perkebunan kopi di Indonesia dikelola oleh rakyat, sedangkan yang dikelola oleh perkebunan besar relatif lebih sedikit.

Kualitas kopi sangat ditentukan antara lain oleh : jenis bahan yang ditanam, faktor lingkungan, panenan, cara pengolahan hasil. Pada perkebunan rakyat biasanya kualitas kopi masih di bawah hasil dari perkebunan besar, dan hal inilah yang mengakibatkan kuantitas dalam memenuhi quota ekspor pada pasar dunia sulit tercapai.Guna memenuhi kualitas, kuantitas dan kontinuitas perdagangan kopi perlu adanya perbaikan dan peningkatan pengusahaan kopi rakyat di Indonesia. Salah satu cara yang dapat dilakukan adalah penyuluhan dalam hal pemilihan bibit kopi yang berkualitas, kultur budidaya, pemanenan dan penanganan pasca panen serta pengolahan hasil. Hal ini menjadi tugas dan tanggung jawab kalangan akademisi di bidang pertanian; instansi terkait dan pemerintah.

Indonesia termasuk lima besar eksportir kopi dunia, negara tujuan utama adalah negara-negara eropa seperti Jerman, Belanda, Italia, selain itu yang cukup kontinu adalah ekspor ke Amerika
Serikat. Lebih lanjut, suatu laporan oleh Organisasi Kopi Internasional menurut ICO, 2005,menunjukkan bahwa harga kopi mengalami penurunan dari tahun ke tahun. Pada tahun 2005, harga kopi ekspor Indonesia menurun dua persen. Walaupun kopi merupakan komoditi ekspor penting, ketidakpastian harga dan selalu terjadi penurunan harga dipasar ekspor maka perlu menyoroti pentingnya pasar kopi domestik. Dengan ukuran pasar sekitar 1600 ton pertahun menurut Biro Pusat Statistik di Jakarta pada tahun 2005, pasar kopi domestik cukup penting dan mempunyai potensi untuk sasaran penjualan.

Pemerintah telah melakukan suatu kampanye, promosi besar untuk mencapai peningkatan permintaan melalui iklan dan pemasaran umum. Di dalam konteks ini menjadi penting untuk memahami sifat alami fungsi permintaan kopi di pasar domestik. Jika elastisitas harga permintaan kopi rendah maka penggunaan faktor seperti iklan dan kampanye pemasaran umum sampai dengan mempromosikan permintaan kopi akan lebih sesuai.

Indonesia merupakan negara penghasil kopi peringkat ke-4 di dunia pada tahun 2002, setelah Brazil, Columbia dan Vietnam. Kopi merupakan salah satu komoditas andalan perkebunan yang mempunyai kontribusi cukup nyata dalam perekonomian indonesaia, yaitu sebagai penyedia lapangan kerja sejak on farm hingga off farm, bahan baku industri, penghasil devisa hingga pengembangan wilayah. Walaupun kopi merupakan salah satu komoditi ekspor 
andalan Indonesia, ternyata belum memberi harapan pada liberalisasi ekonomi tahun 1991 sampai tahun 2005. Data ekspor komoditi pertanian khususnya komoditi kopi pada Biro Pusat Statistik pada tahun 2005, menunjukkan bahwa nilai ekspor kopi Indonesia cenderung mengalami penurunan. Total ekspor komoditi pertanian telah berkurang pada periode tahun 2001-2005.

\section{METODE PENELITIAN}

\section{Waktu Dan Lokasi Penelitian}

Penelitian ini di lakukan pada bulan Pebruari 2020 terhadap usahatani kopi rakyat pada musim panen 2020. Penelitian ini di lakukan di Kecamatan Panti Kabupan Jember, penentuan lokasi penelitian dilakukan secara purposive atau sengaja dengan pertimbangan bahwa Kecamatan tersebut adalah salah satu dari 4 kecamatan diantaranya Jelbuk, Sumberjambe, Ledokombo dan Panti yang mempunyai areal tani terluas selain Kecamatan Silo, namun di keempat kecamatan tersebut masih jarang dijadikan lahan penelitian. Desa terpilih adalah Desa Pakis dan Desa Kemiri dengan pertimbangan sebagai desa dengan populasi petani kopi terbanyak di Kecamatan Panti.

\section{Metode Penelitian}

Metode yang digunakan dalam penelitian ini adalah metode deskriptif yaitu suatu metode dalam peneliti status sekelompok manusia, satu objek, suatu set kondisi, suatu sistem pemikiran ataupun suatu kelas peristiwa pada masa sekarang. Tujuannya adalah untuk membuat diskripsi, gambaran atau lukisan secara sistematis, faktual dan akurat mengenai fakta-fakta, sifat-sifat serta hubungan antar fenomena yang diselidiki ( Nazir, 1985)

\section{Metode Pengumpulan Data}

Dalam penelitian ini digunakan jenis data primer dan data sekunder. Data primer dikumpulkan melalui wawancara langsung dengan responden (petani kopi) menggunakan daftar pertanyaan yang telah dipersiapkan. Data primer yang dikumpulkan berkaitan dengan variabel produktivitas, faktor-faktor produksi, harga output dan biaya produksi, serta profil petani sampel.

Sementara data sekunder diperoleh dari instansi terkait yang berhubungan dengan penelitian ini, terutama perkembangan luas panen, produksi dan produktivitas kopi baik nasional maupun regional yang berasal dari Dinas Pertanian dan Tanaman Pangan Kabupaten Jember. DepartemenPertanian, Badan Pusat Statistik (BPS)dan instansi terkait lainnya.

\section{HASIL DAN PEMBAHASAN}

Hasil penelitian menunjukkan bahwa perilaku petani yang berpendapat kelompok tani sebagai tempat memperoleh ilmu baru yaitu $10 \%$ dari total responden, sebagai memperoleh tempat bantuan yaitu $17,5 \%$, sebagai tempat menjalin kerjasama yaitu $8,75 \%$, dan sebagai tempat berkumpul atau bersosialisasi yaitu $13,75 \%$. Perilaku petani yang paling tinggi adalah sebagai tempat memperoleh bantuan karena dengan adanya bantuan maka petani akan 
mengurangi jumlah baiaya yang dikeluarkannya. Kondisi ini sebenarnya kurang kondusif untuk perkembangan dan kemajuan petani kurang termotivasi untuk mengikuti teknologi usahatani baru dengan prakarsa sendiri. Petani yang tidak mengikuti kelompok tani seharusnya mengikuti kelompok tani agar petani lebih mengenal teknologi baru dan cara mengelola usahatani kopi agar lebih meningkatkan hasil produksi yang maksimal yaitu dengan cara bergabung dengan kelompok tani, mengikuti sekolah lapang dan mengikuti anjuran para PPL.

Menurut Pusluhtan (2002) kelompok tani diadakan untuk melaksanakan fungsi sebagai berikut :

1. Merupakan wadah belajar mengajar bagi anggotanya guna meningkatkan pengetahuan, keterampilan dan sikap (PKS) serta tumbuh dan berkembangnya kemandirian dalam berusaha tani sehingga produktivitasnya meningkat

2. Merupakan tempat untuk memperkuat kerjasama diantara sesama petani dalam kelompoktani dan antar kelompoktani serta dengan pihak lain. Melalui kerjasama ini diharapkan usaha lainnya akan lebih efisien serta lebih mampu menghadapi ancaman, tantangan, hambatan dan gangguan.

3. Usahatani yang dilakukan oleh masing-masing anggota kelompoktani, secara keseluruhan harus dipandang sebagai suatu kesatuan usaha yang dapat dikembangkan untuk mencapai skala ekonomi, baik dipandang dari segi kuantitas, kualitas maupun kontinuitas.

Berdasarkan hal tersebut maka jika persepsi petani terhadap kelompok tani hanya tempat mendapatkan bantuan, maka diperlukan beberapa unsur pengikat kelompok tani dalam bentuk antara lain:

1. Adanya kader tani yang berdedikasi untuk menggerakkan para petani dan kepemimpinannya diterima oleh sesama petani lainnya

2. Adanya kegiatan yang dapat dirasakan manfaatnya oleh sekurang-kurangnya sebagian besar anggotanya dan

3. Adanya dorongan atau motivasi dari tokoh masyarakat setempat untuk menunjang program yang telah ditentukan.

Berdasarkan persepsi petani kopi rakyat yang tidak mengikuti kelompok tani paling besar yaitu tidak tahu bagaimana cara bergabung dengan kelompok tani sebesar $20 \%$. Beberapa hal yang memungkinkan menyebabkan petani tidak bergabung dengan kelompok tani antara lain:

1. Kebanyakan petani yang tidak mengikuti kelompok tani mempunyai lokasi kebun di hutan yang jauh dari pemukiman petani dan akses jalan yang tidak bagus sehingga petani mengalami kelelahan fisik setelah dari lahan akibatnya kurang atau tidak bersemangat mengikuti kegiatan kelompok tani.

2. Dari data profil terlihat bahwa luas lahan petani yang tidak mengikuti kelompok lebih tinggi. Luas yang lebih besar memerlukan tenaga dan pikiran yang lebih banyak untuk 
mengelolanya sehingga minat dan niat untuk bergabung dengan kelompok tani juga berkurang.

3. Dari data profil terlihat bahwa umur petani yang tidak mengikuti kelompok tani lebih tinggi. Petani yang berusia lebih tua relatif lebih cepat mengalami kelelahan fisik, selain itu petani yang lebih berumur cenderung kurang tanggap dengan inovasi dan pengetahuan baru sehingga mengurangi minat untuk bergabung dengan kelompok tani.

Perbedaan produktivitas ini nyata statistik yaitu taraf kepercayaan 99\% sebagaimana analisis uji beda yang terdapat pada Tabel 1

Tabel1. Hasil Analisis Uji t 2 ArahBeda Produktivitas Lahan Usahatani Kopi Rakyat di Kecamatan Panti Kabupaten Jember 2020

\begin{tabular}{lrccc}
\hline \multicolumn{1}{c}{ Uraian } & Rata-rata & $\begin{array}{c}\text { Perbedaan } \\
\text { Rata-rata }\end{array}$ & t-hitung & Signifikansi \\
\hline $\begin{array}{l}\text { Mengikuti Kelompok } \\
\text { Tidak Mengikuti Kelompok }\end{array}$ & $\begin{array}{r}1.340 .365 \\
713.75\end{array}$ & 6,266 & 6,361 & $0,000^{*}$ \\
\hline
\end{tabular}

\section{Efisiensi Penggunaan Biaya Usahatani Kopi Rakyat}

Prinsip dari suatu usahatani termasuk usahatani kopi rakyat adalah menghasilkan produksi yang maksimal dengan menekan penggunaan biaya yang seminimal mungkin atau dengan melakukan efisiensi dalam penggunaan biaya produksi. Tujuan dari kegiatan usahatani adalah untuk memperoleh keuntungan yang setinggi mungkin dengan biaya yang serendah-rendahnya, dan usahatani yang efisien adalah usahatani yang secara ekonomis menguntungkan, demikian juga dengan usahatani kopi rakyat. Analisis R/C merupakan salah satu cara untuk mengetahui tingkat efisiensi biaya dari suatu usahatani.

Tabel. 2 Hasil Uji ANOVA Produksi

Produksi

\section{Descriptives}




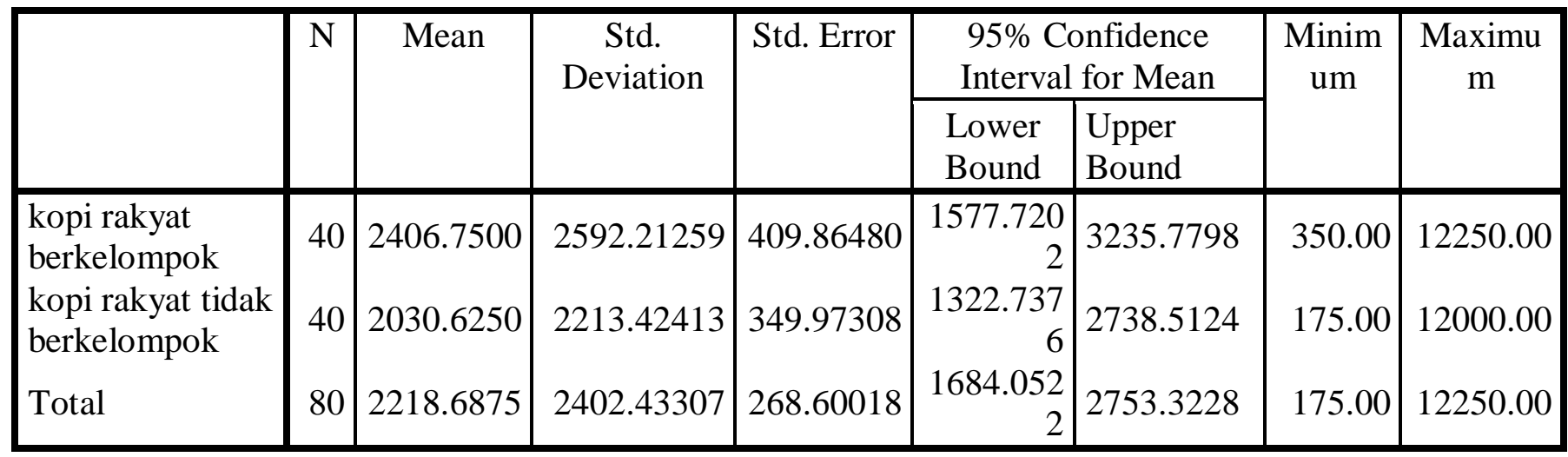

Test of Homogeneity of Variances

Produksi

\begin{tabular}{|r|r|r|r|}
\hline $\begin{array}{c}\text { Levene } \\
\text { Statistic }\end{array}$ & df1 & df2 & Sig. \\
\hline .912 & 1 & 78 & .343 \\
\hline
\end{tabular}

Berdasarkan tabel output "Test Of Homogenity of Variances" di atas diketahui nilai signifikansi. Variabel kopi rakyat berkelompok dan kopi rakyat tidak berkelompok adalah sebesar 0,343. Karena nilai Sig 0,343>0,05 maka sebagaimana dasar pengambilan keputusan dalam uji homogenitas diatas, dapat disimpulkan bahwa varians data kopi rakyat berkelompok dan kopi rakyat tidak berkelompok adalah sama atau homogen.

ANOVA

Produksi

\begin{tabular}{|l|r|r|r|r|r|}
\hline & Sum of Squares & \multicolumn{1}{|c|}{ df } & Mean Square & F & \multicolumn{1}{c|}{ Sig. } \\
\hline Between & 2829400.313 & 1 & 2829400.313 & .487 & .487 \\
Groups & & 78 & 5809406.242 & & \\
Within Groups & 453133686.875 & & & \\
Total & 455963087.188 & 79 & & & \\
\hline
\end{tabular}

Berdasarkan uji ANOVA yang dilakukan terhadap produksi diperoleh hasil $F_{\text {hitung }}=0,487 \mathrm{df3}=1$, df4 $=78$. Pengambilan keputusan berdasarkan perbandingan $F_{\text {hitung }}$ dan $F_{\text {tabel }}$ yaitu jika $F_{\text {hitung }}>\mathrm{F}_{\text {tabel }}$ maka $\mathrm{H}_{0}$ ditolak, $\mathrm{F}_{\text {hitung }}<$ $\mathrm{F}_{\text {tabel }}$ maka $\mathrm{H}_{0}$ diterima. $\mathrm{F}_{\text {hitung }}$ dari output adalah 0,487 sedangkan $F_{\text {tabel }}$ bisa dihitung pada tabel F. Dari tabel F didapat angka 3.96347, $\mathrm{F}$ tabel bisa diperoleh secara praktis menggunakan software Excel dengan menulis pada sel = FINV $(0,05 ; 1 ; 78)$. Dengan tabel seperti diatas terlihat bahwa $\mathrm{F}_{\text {hitung }}<\mathrm{F}_{\text {tabel }}, 0,487$ 
< 3.96347 maka $\mathrm{H}_{0}$ diterima yang artinya tidak terdapat perbedaan yang signifikan, maka tidak perlu dilanjutkan dengan uji lanjutan.Koefisien GDP Riil sebesar 4.78E-09, maka GDP Riil berhubungan positif. Artinya ketika GDP Riil naik US\$ 1 maka volume ekspor kopi akan naik sebesar 4.78E-09 ton, dengan asumsi variabel lain tetap. Begitu pula sebaliknya, jika GDP Riil turun 1 US\$ maka volume ekspor akan turun sebesar 4.78E-09 ton. Penjelasan diatas

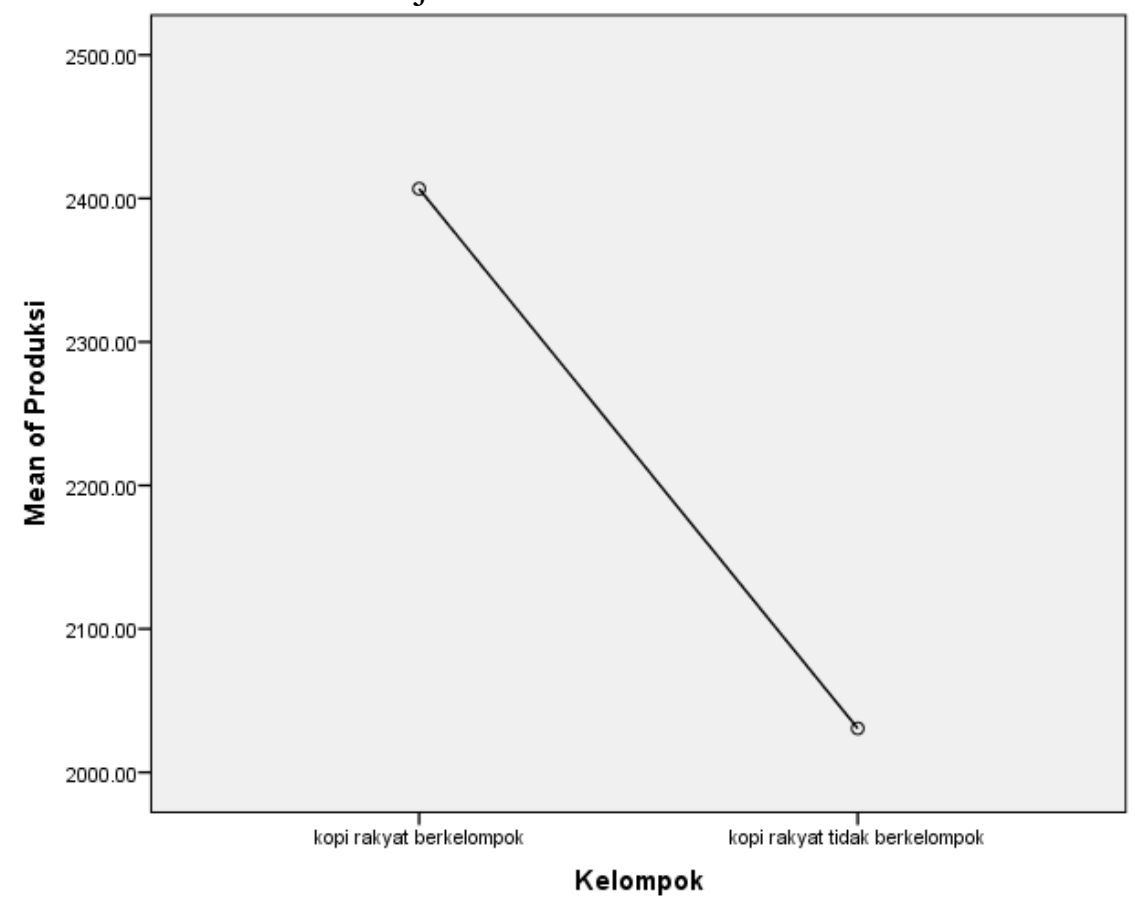

Tabel 3 Hasil Uji ANOVA Penerimaan

Penerimaan menunjukkan bahwa hasil dari penelitian ini sesuai dengan hipotesa yang telah dijelakan, bahwa GDP Riil berpengaruh signifikan terhadap volume ekspor kopi indonesia. hasil dari penelitian ini sesuai dengan penelitian (lukman, 2012) yang menyatakan bahwa meningkatnya pendapatan masyarakat menyebabkan permintaan produk kopi pun meningkat, dan sebaliknya 


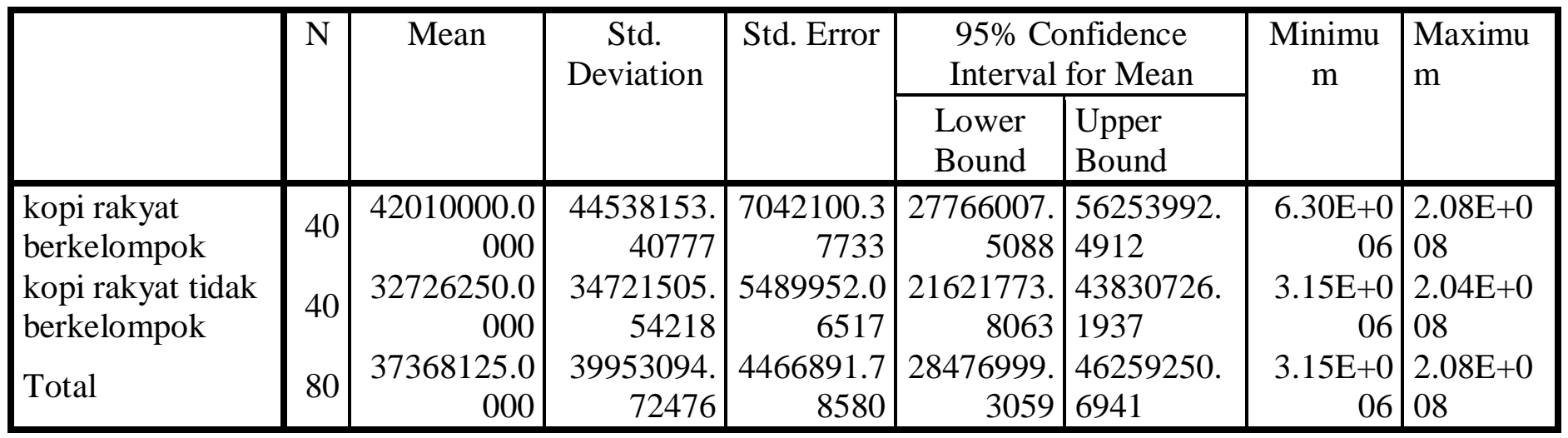

Test of Homogeneity of Variances

Penerimaan

\begin{tabular}{|r|r|r|r|}
\hline $\begin{array}{c}\text { Levene } \\
\text { Statistic }\end{array}$ & df1 & df2 & Sig. \\
\hline 2.113 & 1 & 78 & .150 \\
\hline
\end{tabular}

Berdasarkan tabel output "Test Of Homogenity of Variances" di atas diketahui nilai signifikansi. Variabel kopi rakyat berkelompok dan kopi rakyat tidak berkelompok adalah sebesar 0,343. Karena nilai Sig 0,150>0,05 maka sebagaimana dasar pengambilan keputusan dalam uji homogenitas diatas, dapat disimpulkan bahwa varians data kopi rakyat berkelompok dan kopi rakyat tidak berkelompok adalah sama atau homogen.

ANOVA

Penerimaan

\begin{tabular}{|l|r|r|c|c|c|}
\hline & Sum of Squares & df & Mean Square & F & Sig. \\
\hline Between & 172371250000 & 1 & 1723760281250 & 1.081 & .302 \\
Groups & 1243799721875 & 78 & 1594044871.80 & & \\
Within Groups & 1261037387500 & 79 & & & \\
Total & & & \\
\hline
\end{tabular}

Berdasarkan uji ANOVA yang dilakukan terhadap penerimaan diperoleh hasil $F_{\text {hitung }}=1.081 \mathrm{df3}=1$, df4 $=78$. Pengambilan keputusan berdasarkan perbandingan $F_{\text {hitung }}$ danF $F_{\text {tabel }}$ yaitu jika $F_{\text {hitung }}>\mathrm{F}_{\text {tabel }}$ maka $\mathrm{H}_{0}$ ditolak, $\mathrm{F}_{\text {hitung }}<$ $\mathrm{F}_{\text {tabel }}$ maka $\mathrm{H}_{0}$ diterima. $\mathrm{F}_{\text {hitung }}$ dari output adalah 1.081 sedangkan $F_{\text {tabel }}$ bisa dihitung pada tabel F. Dari tabel F didapat angka 3.96347, $\mathrm{F}$ tabel bisa diperoleh secara praktis menggunakan software Excel dengan menulis pada sel = FINV $(0,05 ; 1 ; 78)$. Dengan tabel seperti diatas terlihat bahwa $\mathrm{F}_{\text {hitung }}<\mathrm{F}_{\text {tabel }}, 1.081$ $<3.96347$ maka $\mathrm{H}_{0}$ diterima yang artinya tidak terdapat perbedaan yang signifikan, 
maka tidak perlu dilanjutkan dengan uji

lanjutan.

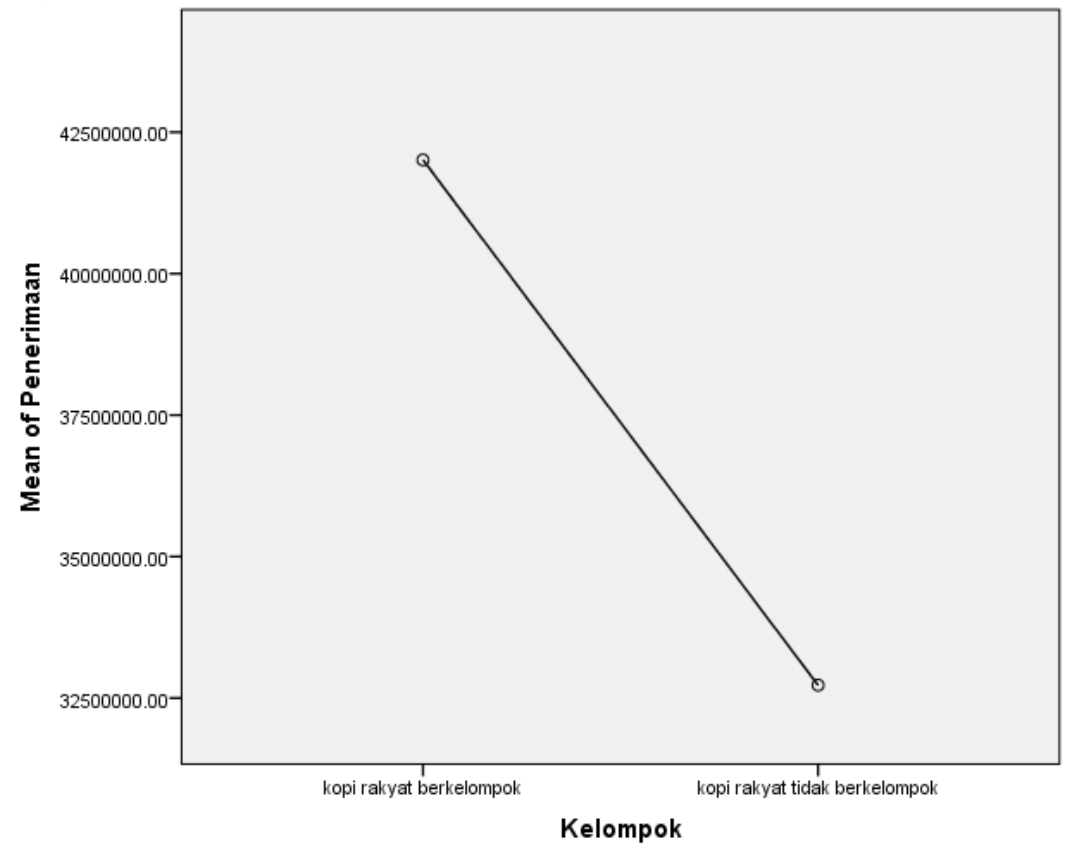

Tabel 4.Hasil Uji ANOVA Biaya

Biaya

\section{Descriptives}

\begin{tabular}{|c|c|c|c|c|c|c|c|c|}
\hline & \multirow[t]{2}{*}{$\mathrm{N}$} & \multirow[t]{2}{*}{ Mean } & \multirow[t]{2}{*}{ Std. Deviation } & \multirow[t]{2}{*}{ Std. Error } & \multicolumn{2}{|c|}{ 95\% Confidence Interval for Mean } & \multirow[t]{2}{*}{ Minimum } & \multirow[t]{2}{*}{ Maximum } \\
\hline & & & & & Lower Bound & Upper Bound & & \\
\hline kopi rakyat berkelompok & 40 & 12050396.1063 & 9646997.49323 & 1525324.23303 & 8965136.6300 & 15135655.5825 & $3.00 \mathrm{E}+006$ & $4.33 \mathrm{E}+007$ \\
\hline $\begin{array}{l}\text { kopi rakyat tidak } \\
\text { berkelompok }\end{array}$ & 40 & 15742290.7813 & 13836446.09999 & 2187734.21991 & 11317180.6392 & 20167400.9233 & $1.73 \mathrm{E}+006$ & $7.25 \mathrm{E}+007$ \\
\hline Total & 80 & 13896343.4438 & 11996076.35063 & 1341202.10916 & 11226747.4236 & 16565939.4639 & $1.73 \mathrm{E}+006$ & $7.25 \mathrm{E}+007$ \\
\hline
\end{tabular}

(Data SPSS, diolah 2020)

\section{Test of Homogeneity of Variances}

Biaya

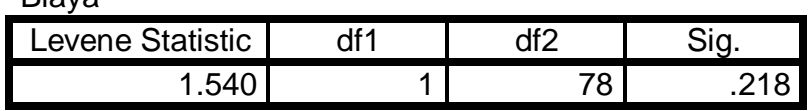

Berdasarkan tabel output "Test Of Homogenity of Variances" di atas diketahui nilai signifikansi. Variabel kopi rakyat berkelompok dan kopi rakyat tidak berkelompok adalah sebesar 0,343. Karena nilai Sig 0,218>0,05 maka sebagaimana dasar pengambilan keputusan dalam uji homogenitas diatas, dapat disimpulkan bahwa varians data kopi rakyat berkelompok dan kopi rakyat tidak berkelompok adalah sama atau homogen. 
Biaya

ANOVA

\begin{tabular}{|l|r|r|l|r|r|}
\hline & Sum of Squares & df & Mean Square & F & Sig. \\
\hline Between Groups & 272601767.220 & 1 & 272601767.220 & 1.916 & .170 \\
Within Groups & 110974060.000 & 78 & 142255977.700 & & \\
Total & 113689928.000 & 79 & & & \\
\hline
\end{tabular}

Berdasarkan uji ANOVA yang dilakukan terhadap Biaya diperoleh hasil $\mathrm{F}_{\text {hitung }}=1.916 \mathrm{df} 3=1, \mathrm{df} 4=78$. Pengambilan keputusan berdasarkan perbandingan $F_{\text {hitung }}$ dan $F_{\text {tabel }}$ yaitu jika $\mathrm{F}_{\text {hitung }}>\mathrm{F}_{\text {tabel }}$ maka $\mathrm{H}_{0}$ ditolak, $\mathrm{F}_{\text {hitung }}<$ $\mathrm{F}_{\text {tabel }}$ maka $\mathrm{H}_{0}$ diterima. $\mathrm{F}_{\text {hitung }}$ dari output adalah 1.916 sedangkan $\quad \mathrm{F}_{\text {tabel }}$ bisa dihitung pada tabel F. Dari tabel F didapat angka 3.96347, $\mathrm{F}$ tabel bisa diperoleh secara praktis menggunakan software Excel dengan menulis pada sel = $\operatorname{FINV}(\mathbf{0 , 0 5} ; \mathbf{1 ; 7 8})$. Dengan tabel seperti diatas terlihat bahwa $\mathrm{F}_{\text {hitung }}<\mathrm{F}_{\text {tabel }}, 1.916$ $<3.96347$ maka $\mathrm{H}_{0}$ diterima yang artinya tidak terdapat perbedaan yang signifikan, maka tidak perlu dilanjutkan dengan uji lanjutan.

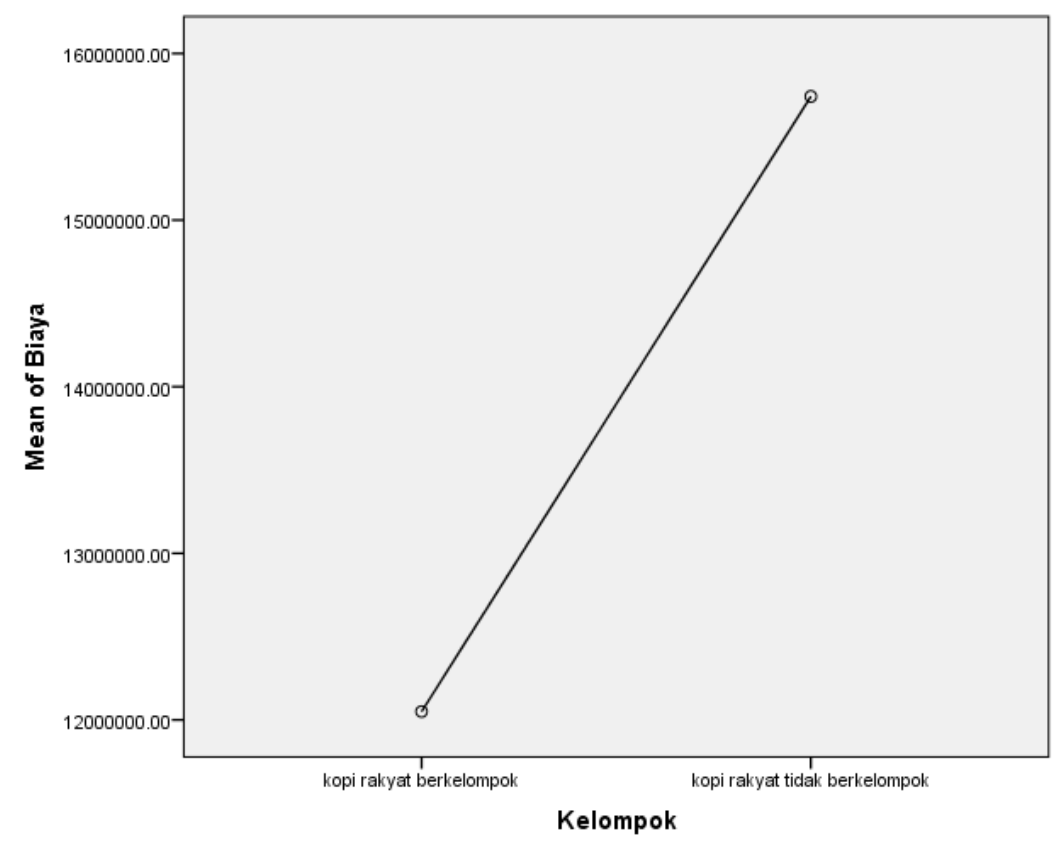

Tabel 5. Hasil Uji ANOVA Keuntungan 
Keuntungan

\section{Descriptives}

\begin{tabular}{|c|c|c|c|c|c|c|c|c|}
\hline & \multirow[t]{2}{*}{$\mathrm{N}$} & \multirow[t]{2}{*}{ Mean } & \multirow[t]{2}{*}{ Std. Deviation } & \multirow[t]{2}{*}{ Std. Error } & \multicolumn{2}{|c|}{ 95\% Confidence Interval for Mean } & \multirow[t]{2}{*}{ Minimum } & \multirow[t]{2}{*}{ Maximum } \\
\hline & & & & & Lower Bound & Upper Bound & & \\
\hline kopi rakyat berkelompok & 40 & 29959603.8940 & 36178796.49140 & 5720369.99583 & 18389063.4442 & 41530144.3438 & $2.72 \mathrm{E}+006$ & $1.65 \mathrm{E}+008$ \\
\hline kopi rakyat tidak berkelompok & 40 & 16983959.2200 & 21918023.72947 & 3465543.83974 & 9974235.1624 & 23993683.2776 & 524715.00 & $1.31 \mathrm{E}+008$ \\
\hline Total & 80 & 23471781.5570 & 30429467.14867 & 3402117.85318 & 16700035.3609 & $\begin{array}{l}30243527.7 \\
51\end{array}$ & 524715.00 & $1.65 \mathrm{E}+008$ \\
\hline
\end{tabular}

Keuntungan

Test of Homogeneity of Variances

\begin{tabular}{|c|c|c|c|}
\hline Levene Statistic & df1 & df2 & Sig. \\
\hline 5.245 & 1 & 78 & .025 \\
\hline
\end{tabular}

Berdasarkan tabel output "Test Of Homogenity of Variances" di atas diketahui nilai signifikansi. Variabel kopi rakyat berkelompok dan kopi rakyat tidak berkelompok adalah sebesar 0,343. Karena nilai Sig 0,025>0,05 maka

\section{ANOVA}

Keuntungan

\begin{tabular}{|l|r|r|r|r|r|}
\hline & Sum of Squares & df & Mean Square & F & Sig. \\
\hline Between Groups & 336734194.500 & 1 & 3367318094.50 & 3.764 & .056 \\
Within Groups & 69782817800.0 & 78 & 8946585997.40 & & \\
Total & 7315225888.00 & 79 & & & \\
\hline
\end{tabular}

Berdasarkan uji ANOVA yang dilakukan terhadap Biaya diperoleh hasil $F_{\text {hitung }}=3.764$ df3 $=1$, df4 $=78$. Pengambilan keputusan berdasarkan perbandingan $F_{\text {hitung }}$ danF $F_{\text {tabel }}$ yaitu jika $\mathrm{F}_{\text {hitung }}>\mathrm{F}_{\text {tabel }}$ maka $\mathrm{H}_{0}$ ditolak, $\mathrm{F}_{\text {hitung }}<$ $\mathrm{F}_{\text {tabel }}$ maka $\mathrm{H}_{0}$ diterima. $\mathrm{F}_{\text {hitung }}$ dari output adalah 3.764 sedangkan $F_{\text {tabel }}$ bisa dihitung pada tabel F. Dari tabel F sebagaimana dasar pengambilan keputusan dalam uji homogenitas diatas, dapat disimpulkan bahwa varians data kopi rakyat berkelompok dan kopi rakyat tidak berkelompok adalah sama atau homogen.

didapat angka 3.96347, $\mathrm{F}$ tabel bisa diperoleh secara praktis menggunakan software Excel dengan menulis pada sel = FINV $(0,05 ; 1 ; 78)$. Dengan tabel seperti diatas terlihat bahwa $\mathrm{F}_{\text {hitung }}<\mathrm{F}_{\text {tabel }}, 3.764$ $<3.96347$ maka $\mathrm{H}_{0}$ diterima yang artinya tidak terdapat perbedaan yang signifikan, maka tidak perlu dilanjutkan dengan uji lanjutan. 


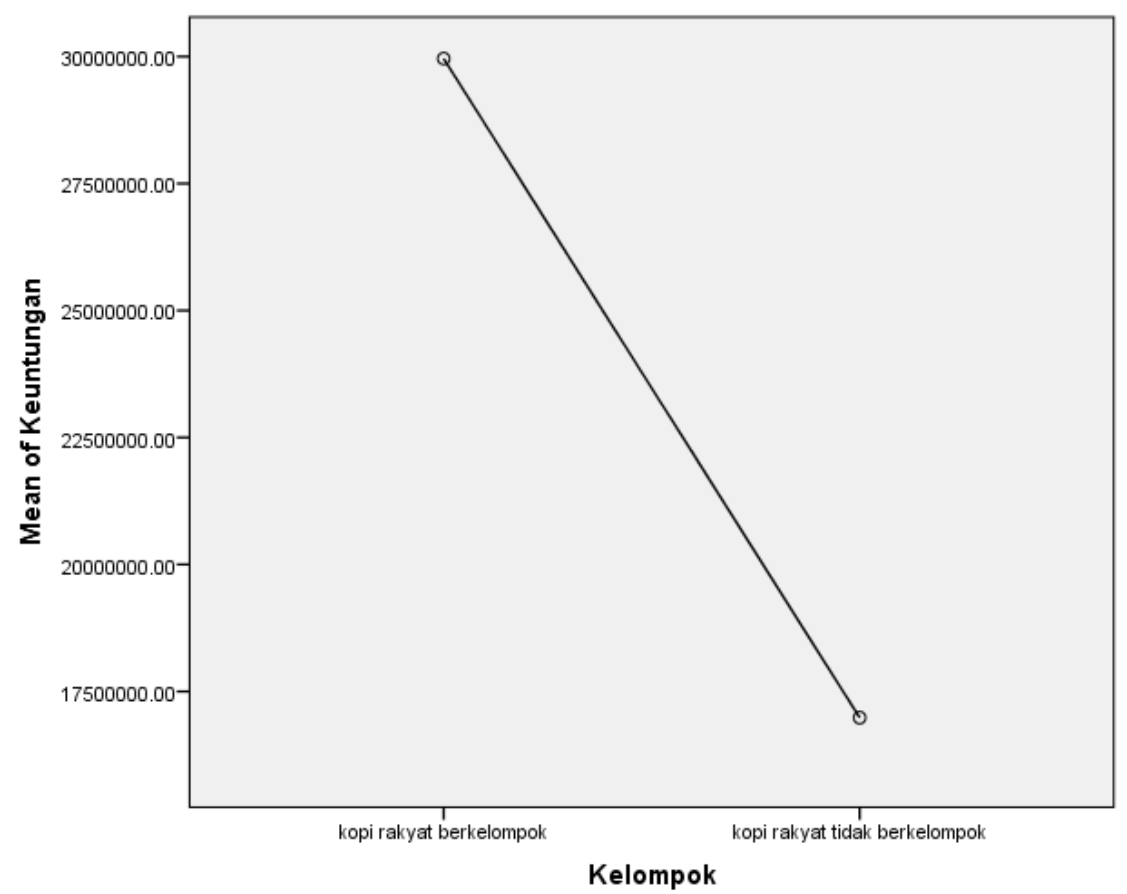

Tabel 6. Hasil Uji ANOVA Harga

Harga

\section{Descriptives}

\begin{tabular}{|c|c|c|c|c|c|c|c|c|}
\hline & \multirow[t]{2}{*}{$\mathrm{N}$} & \multirow[t]{2}{*}{ Mean } & \multirow{2}{*}{$\begin{array}{c}\text { Std. } \\
\text { Deviation }\end{array}$} & \multirow[t]{2}{*}{ Std. Error } & \multicolumn{2}{|c|}{ 95\% Confidence Interval for Mean } & \multirow[t]{2}{*}{ Minimum } & \multirow[t]{2}{*}{ Maximum } \\
\hline & & & & & Lower Bound & Upper Bound & & \\
\hline kopi rakyat berkelompok & 40 & 17537.5000 & 485.52773 & 76.76868 & 17382.2207 & 17692.7793 & 17000.00 & 18000.00 \\
\hline kopi rakyat tidak berkelompok & 40 & 16825.0000 & 1692.93403 & 267.67637 & 16283.5734 & 17366.4266 & 12000.00 & 18000.00 \\
\hline Total & 80 & 17181.2500 & 1288.32083 & 144.03865 & 16894.5482 & 17467.9518 & 12000.00 & 18000.00 \\
\hline
\end{tabular}

Test of Homogeneity of Variances

\begin{tabular}{|c|c|c|c|}
\hline Levene Statistic & $\mathrm{df1}$ & df2 & Sig. \\
\hline 5.241 & 1 & 78 & .025 \\
\hline
\end{tabular}

Berdasarkan tabel output "Test Of Homogenity of Variances" di atas diketahui nilai signifikansi. Variabel kopi rakyat berkelompok dan kopi rakyat tidak berkelompok adalah sebesar 0,343. Karena nilai Sig 0,025>0,05 maka sebagaimana dasar pengambilan keputusan dalam uji homogenitas diatas, dapat disimpulkan bahwa varians data kopi rakyat berkelompok dan kopi rakyat tidak berkelompok adalah sama atau homogen. 


ANOVA
\begin{tabular}{|l|r|r|r|r|r|}
\hline \multicolumn{1}{|c|}{ Harga } & Sum of Squares & df & Mean Square & F & Sig. \\
\hline Between Groups & 10153125.000 & 1 & 10153125.000 & 6.547 & .012 \\
Within Groups & 120968750.000 & 78 & 1550881.410 & & \\
Total & 131121875.000 & 79 & & & \\
\hline
\end{tabular}

Berdasarkan uji ANOVA yang dilakukan terhadap Harga diperoleh hasil $\mathrm{F}_{\text {hitung }}=6.547 \mathrm{df} 3=1, \mathrm{df} 4=78$. Pengambilan keputusan berdasarkan perbandingan $F_{\text {hitung }}$ danF $F_{\text {tabel }}$ yaitu jika $\mathrm{F}_{\text {hitung }}>\mathrm{F}_{\text {tabel }}$ maka $\mathrm{H}_{0}$ ditolak, $\mathrm{F}_{\text {hitung }}<$ $\mathrm{F}_{\text {tabel }}$ maka $\mathrm{H}_{0}$ diterima. $\mathrm{F}_{\text {hitung }}$ dari output adalah 6.547 sedangkan $\quad F_{\text {tabel }}$ bisa dihitung pada tabel F. Dari tabel F didapat angka 3.96347, $\mathrm{F}$ tabel bisa diperoleh secara praktis menggunakan software Excel dengan menulis pada sel = FINV $(0,05 ; 1 ; 78)$. Dengan tabel seperti diatas terlihat bahwa $F_{\text {hitung }}>F_{\text {tabel }}, 6.547$ > 3.96347 maka $\mathrm{H}_{0}$ ditolak yang artinya terdapat perbedaan yang signifikan, maka perlu dilanjutkan dengan uji lanjutan.

Melihat keadaan tersebut industry kopi yang mengalami kemajuan akan tetapi dibalik semua itu ada masalah serius yaitu produksi dan ekspor kopi yang mengalami fluktuasi/naik turun, maka pemerintah telah menerapkan bebrbagai kebijakan yang memiliki efek langsung maupun tidak langsung terhadap industry kopi nasional dengan harapan industry kopi nasional dapat mengalami kemajuan. Kebijakan pemerintah tersebut mempunyai dimensi yang cukup luas meliputi kebijakan luas areal, produksi, ekspor kopi, dan kebijakanharga. 


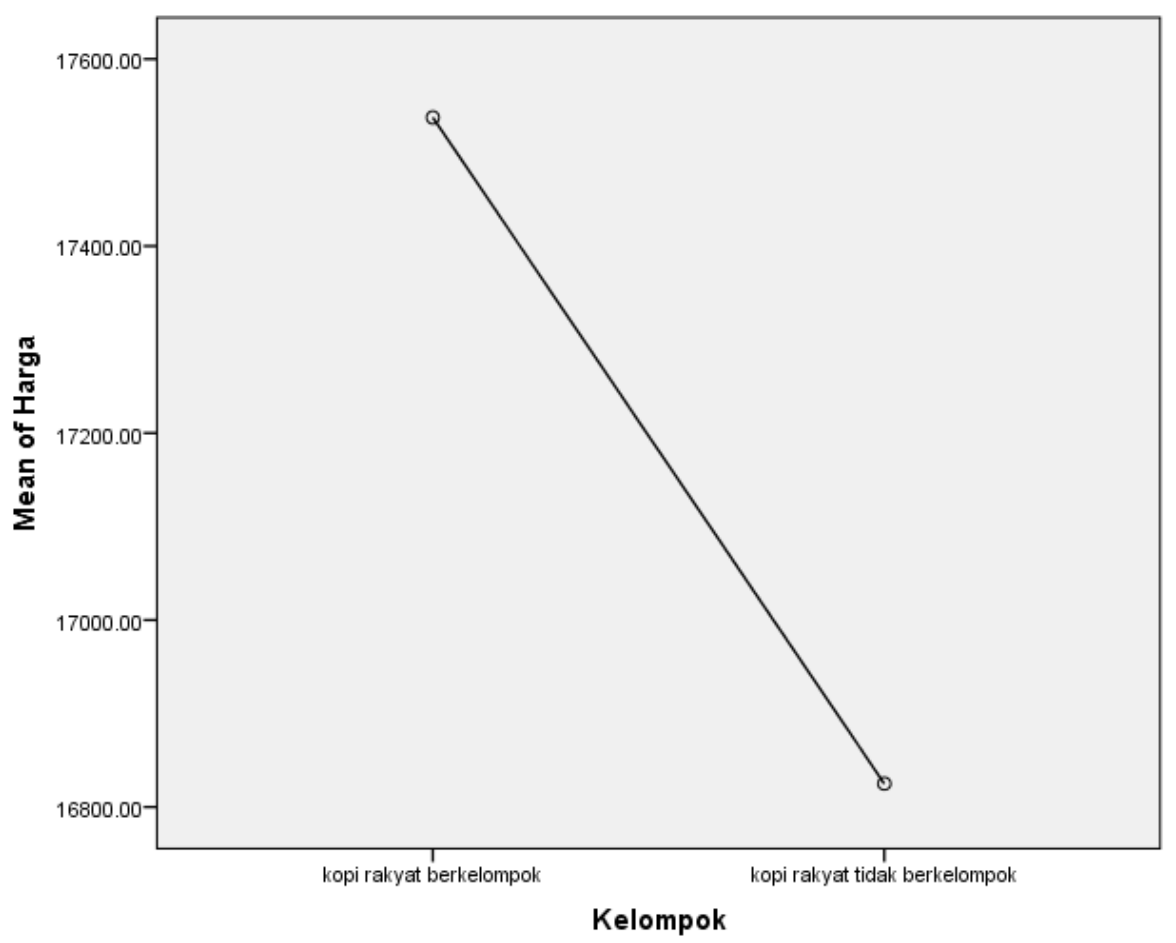

\section{KESIMPULAN}

1. Test Of Homogenity of Variances" di atas diketahui nilai signifikansi. Variabel kopi rakyat berkelompok dan kopi rakyat tidak berkelompok adalah sebesar 0,343. Karena nilai Sig 0,343>0,05 maka sebagaimana dasar pengambilan keputusan dalam uji homogenitas diatas, dapat disimpulkan bahwa varians data kopi rakyat berkelompok dan kopi rakyat tidak berkelompok adalah sama atau homogen.

2. Ada perbedaan produktivitas yang signifikan antara usahatani kopi rakyat yang mengikuti kelompok tani dan petani yang tidak mengikuti kelompok tani di Kecamatan Panti Kabupaten Jember pada taraf kepercayaan 99\%. Produktivitas kopi rakyat yang mengikuti kelompoksebesar $1.340,365 \mathrm{~kg} / \mathrm{ha}$ sedangkan petani yang tidak mengikuti kelompok tani sebesar $713,75 \mathrm{~kg} / \mathrm{ha}$.

3. Ada perbedaan efisiensi penggunaan biaya yang signifikan pada usahatani kopi rakyat yang mengikuti kelompok tani dan yang tidak mengikuti kelompok tani di Kecamatan Panti Kabupaten Jember pada taraf kepercayaan $99 \%$. Efisiensi biaya (R/C) pada petani yang mengikuti kelompok tani adalah3,18, lebih tinggi dibanding petani yang tidak mengikuti kelompok tani sebesar 2,08.

4. Ada perbedaan keuntungan yang signifikan pada usahatani kopi rakyat yang mengikuti kelompok tani dan 
yang tidak mengikuti kelompok tani di Kecamatan Panti Kabupaten Jember, pada taraf kepercayaan 99\%.Keuntungan yang diperoleh petani yang mengikuti kelompoksebesar Rp 15.804.072 per hektar/tahun,lebih tinggi dibandingkan petani yang tidak mengikuti kelompok yaitu sebesar Rp 6.034,365 per hektar/tahun.

5. Uji ANOVA yang dilakukan terhadap produksi diperoleh hasil $F_{\text {hitung }}=0,487 \mathrm{df} 3=1, \mathrm{df} 4=78$. Pengambilan keputusan berdasarkan perbandingan $F_{\text {hitung }}$ danF $F_{\text {tabel }}$ yaitu jika $F_{\text {hitung }}>\mathrm{F}_{\text {tabel }}$ maka $\mathrm{H}_{0}$ ditolak, $\mathrm{F}_{\text {hitung }}<\mathrm{F}_{\text {tabel }}$ maka $\mathrm{H}_{0}$ diterima. Fhitung dari output adalah 0,487 sedangkan $F_{\text {tabel }}$ bisa dihitung pada tabel F. Dari tabel F didapat angka 3.96347, F tabel bisa diperoleh secara praktis menggunakan software Excel dengan menulis pada sel = FINV(0,05;1;78). Dengan tabel seperti diatas terlihat bahwa $F_{\text {hitung }}<$ $\mathrm{F}_{\text {tabel}}, 0,487<3.96347$ maka $\mathrm{H}_{0}$ diterima yang artinya tidak terdapat perbedaan yang signifikan, maka tidak perlu dilanjutkan dengan uji lanjutan

DAFTAR PUSTAKA

Amir, M.S., 1993. Syarat Mutu Ekspor

Kopi GB atau OIB, Seluk Beluk dan

Tehnik Perdagangan Luar Negri. PT.

Pustaka Bina Presindo. Jakarta.

Badan Pusat StatistikKabupaten Jember, 2020.Kabupaten Jember Dalam

Angka.

http://www.bps.go.id/tnmn_pgn.php?kat= $\underline{3}$
Budiono, 1982. Ekonomi Mikro.

BPFE. Yogyakarta.

Ditjen Perkebunan, 2008. Statistik

Perkebunan Indonesia. Jakarta.

Dinas Kehutanan dan Perkebunan

Kabupaten Jember, 2012. Tidak di publikasikan. Jember.

Djamali, R.A. 2000. Manajemen Usaha

Tani. Politeknik Negri Jember. Jember.

Hariadi, 2004. Kajian Faktor-Faktor yang Berpengaruh Terhadap Kelompok Tani Sebagai Unit Belajar, Kerjasama Produksi dan Usaha. Universitas Gadjah Mada. Yogyakarta.

Heady, O.E, and J.H. Dillon, 2002.

Agricultural

Production.Iowa State

University Press.Ames.

Hernanto, 1995. Ilmu Usahatani.

Penebar Swadaya. Jakarta.

Lubis. 2012. Dasar-Dasar Statistika.

Cetakan ke Sepuluh.

Bandung.

Lukman. (2012). Pengaruh harga

dan faktor eksternal terhadap permintaan ekspor kopi di Indonesia.Signifikan, Vol.1 No 2.

Mardikanto, 1993. Penyuluhan Pembangunan Pertanian. 
Sebelas Maret University

Press Surakarta.

Miller, R. LeRoy dan R. E. Meiners, 2000. Teori Mikro

Ekonomi Intermediate, Penerjemah Haris

Munandar. PT. Raja

Grafindo Persada. Jakarta

Nazir, M, 1985. Metode Penelitian.

Ghalia Indonesia. Jakarta

Prayitno, H. dan L. Arsyad, 1987. Petani desa dan Kemiskinan. BPFE. Yogyakarta

Prayuginingsih, H. dkk. 2013. Model Peningkatan Daya Saing Kopi Rakyat Sebagai Upaya Untuk Memperkokoh Ekonomi Masyarakat Pinggir Hutan. Laporan Penelitian Hibah Bersaing. Fakultas Pertanian. Universitas Muhammadiyah Jember. Jember

Rahardja, 2000. Teori Ekonomi Mikro

(Suatu Pengantar).

Fakultas Ekonomi. Universitas Indonesia. Jakarta.

Soekartawi, 1987. Prinsip Dasar Ekonomi Pertanian Teori dan Aplikasinya. CV Rajawali. Jakarta.

Soekartawi, 1990. Teori Ekonomi Produksi dengan Pokok Bahasan Analisis Fungsi Cobb-Douglas. CV Rajawali. Jakarta.

Soekartawi, 1994. Agribisnis Teori dan Aplikasinya. Rajawali Press. Jakarta.
Soekartawi, 1995. Analisis Usahatani. UI-Press. Jakarta.

Soekartawi, 2002. Teori Ekonomi

Produksi dengan Pokok Bahasan Analisis Fungsi Cobb-Douglas. Cetakanke 3. RajawaliPress. Jakarta.

Soekartawi, 2003. Agribisnis Teori dan Aplikasinya. PT. Raja Grafindo Persada. Jakarta.

Sukirno, S., 2001. Pengantar Teori

Mikro ekonomi.

Edisikedua. Raja Grafindo.

JakartaSupranto, 2009.

Ekonometrika 1.BPFE.

Yogyakarta

SPSS,2019. Program Versi 20, Badan Statistika ITB, Bandung

Hariadi, S.S., 2004. KajianFaktor-

Faktor yang Berpengaruh terhadap Kelompok Tani sebagai Unit Belajar, Kerja Sama Produksi dan Usaha. Ringkasan. Disertasi Universitas Gadjah Mada. Yogyakarta.

Hernanto,F., 1995. Ilmu Usahatani.

PenebarSwadaya. Jakarta.

Yu, M. 2010. Trade, democracy, and the gravity equation.Journal of Development Economics 91 (2): 289-300.

Yuniarti, D. 2007. Analisis determinan perdagangan bilateral Indonesia pendekatan gravity model. Jurnal Ekonomi Pembangunan 12 (2): 99-109. 